\title{
Childhood brain tumours, early infections and immune stimulation: A pooled analysis of the ESCALE
} and ESTELLE case-control studies (SFCE, France)

\section{Authors}

Judith E Lupatsch ${ }^{1,2}$, Helen D Bailey ${ }^{1}$, Brigitte Lacour ${ }^{1,3}$, Christelle Dufour ${ }^{4}$, Anne-Isabelle Bertozzi ${ }^{5}$, Pierre Leblond6, Cécile Faure-Conter77, Isabelle Pellier ${ }^{8}$, Claire Feycon ${ }^{9}$, François Doz ${ }^{10}$ Stéphanie Puget $^{11}$, Stéphane Ducassou ${ }^{12}$, Laurent Orsi ${ }^{1}$, Jacqueline Clavel ${ }^{1,3}$

\section{Affiliations}

1 UMRS 1153, INSERM, Université Paris-Descartes, Université Sorbonne-Paris-Cité, CRESSEPICEA Epidémiologie des cancers de l'enfant et de l'adolescent, Paris, France

2 Institute of Social and Preventive Medicine, University of Bern, Bern, Switzerland

3 RNCE - National Registry of Childhood Cancers, Inserm, Villejuif and CHU de Nancy, France

4 Gustave Roussy, Département de cancérologie de l'enfant et de l'adolescent, Villejuif, France

5 Unité d' Hémato-Immuno-Oncologie pédiatrique, Pôle Pédiatriqe, CHU Toulouse, France

6 Pediatric Oncology Unit, Oscar Lambret Comprehensive Cancer Center, Lille, France

7 Institut d'hématologie et d'oncologie pédiatrique, IHOPe, Centre Léon Bérard, Lyon, France

8 Unité immuno-hémato-oncopédiatrie, CHU d'Angers, Angers, France

9 Clinique de pédiatrie, Hôpital Couple Enfant, CHU Grenoble-Alpes, Grenoble, France

10 Oncology Center SIREDO (Care Innovation Research in Children, Adolescents and Young Adults Cancer), Institut Curie and Université Paris Descartes, Paris, France

11 Service de neurochirurgie pédiatrique, Hôpital Necker-Enfants malades, Université Paris Descartes, Sorbonne Paris Cité, Paris, France

12 Service d'onco-hématologie pédiatrique, Hôpital Pellegrin Tripode, Bordeaux, France

\section{Short title}

Childhood brain tumours and infections

\section{Correspondence}

Judith Lupatsch

INSERM U1153, Epidemiology and Biostatistics Sorbonne Paris Cité (CRESS)

Epidemiology of childhood and adolescent cancers

16 avenue Paul Vaillant Couturier - Bat 15/16, 94807 Villejuif Cedex, France

+33145596020

judith.lupatsch@inserm.fr 
Number of words: 4573

Number of words abstract: 244

Number of Tables: 4

Online supplement: yes 


\section{Abstract}

Background: Few studies have investigated whether early infections and factors potentially related to early immune stimulation might be involved in the aetiology of childhood brain tumours (CBT). In this study, we investigated the associations between CBT with early day-care attendance, history of early common infections, atopic conditions (asthma/wheezing, eczema, allergic rhinitis), early farm residence/visits and contact with animals.

Methods: We pooled data from two nationwide French case-control studies, the ESCALE and ESTELLE studies. Children with a CBT diagnosed between 1 and 14 years of age were identified directly from the French National Registry of Childhood Cancers, while population controls were recruited from telephone subscribers. Odds-ratios (OR) and 95\% confidence intervals (CI) were estimated using logistic regression adjusted for potential confounders.

Results: The analyses included 469 cases and 2719 controls. We found no association between attending a day-care centre (OR: $0.9,95 \% \mathrm{CI}$ : 0.7-1.2) or having had repeated common infections (OR: $0.9,95 \% \mathrm{CI}: 0.7-1.2)$ in the first year of life and the risk of CBT. There was also no association with a history of asthma/wheezing (OR: 0.8, 95\%CI: 0.56-1.1). Farm visits (OR: 0.6, 95\%CI: 0.5-0.8) as well as contact with pets (OR: 0.8, 95\%CI: 0.6-1.0) in the first year of life were inversely associated with CBT. Results for subtypes were similar.

Conclusions: Our findings suggest a protective effect of early farm visits and contact with pets, but not with other markers of early immune stimulation. This might be related to immune stimulation but needs further investigation. 


\section{Keywords}

Children, central nervous system tumours, brain tumours, risk factors, day-care, infections, atopy, allergies, farm, animals, case control study

Highlights

- We pooled data from two French case-control studies (469 cases and 2719 controls).

- Farm visits and contact with pets in early life were inversely associated with childhood brain tumours (CBT).

- Day-care in early life was not associated with CBT.

- A history of common infections or atopic conditions were not associated with CBT.

\section{Abbreviations}

CBT Childhood brain tumours

ICCC-3 International Classification of Childhood Cancer $3^{\text {rd }}$ edition

SFCE Société Française de lutte contre les Cancers et leucémies de l'Enfant et de l'adolescent (French society against childhood and adolescent cancers and leukaemias)

ICDO-3 International Classification of Diseases-Oncology

ENT ear-nose-throat

URTI upper respiratory tract infections

LRTI lower respiratory tract infections

OR odds ratio

CI confidence interval

UKCCS United Kingdom Childhood Cancer 


\section{Introduction}

After leukaemias, brain tumours are the second most common type of childhood cancer. With about 400 cases diagnosed in mainland France every year (3.6 per 100,000 child-years), they represent about $23 \%$ of incident cases of childhood cancer [1]. Childhood brain tumours (CBT) are classed into large heterogeneous groups according to the ICCC-3 classification [2], with about 10\% of ependymomas and plexus choroid tumours, 38\% of astrocytomas, $21 \%$ of embryonal tumours, and $16 \%$ of other gliomas in France mainland [1] . On the average, the five year survival rate in France is about $72 \%$, but with wide variations by age and subtype [3].

The aetiology of CBT is generally unknown. The only established environmental risk factor is ionising radiation at medium or high doses [4,5]. Some genetic dispositions, such as neurofibromatosis, tuberous sclerosis, and Li-Fraumeni syndrome, are also linked with a higher risk of CBT. Suspected risk factors include exposure to pesticides, traffic pollution, parents' occupational exposure, radiofrequencies, parental age, maternal smoking, alcohol use and nutrition $[4,5]$.

Early infections and factors related to early immune stimulation have been mostly studied for childhood leukaemias [6] but might also be involved in the development of CBT. To date, there are only a few studies of potential infections or immunological markers and their association with CBT. History of early common infections has been rarely researched and so far there is no evidence of an association with CBT [7]. Exposure to common infections in infants is difficult to ascertain retrospectively. Birth order [8,9] or attending day-care centres $[10,11]$, which favour early infections through contact with other children, can be used as proxy indicators. Studies which have looked at the association between these markers of infection and CBT have produced mixed findings [7,12-17]. Indicators of abnormal immune system responses include the tendency for atopic conditions such as asthma/wheezing, eczema and allergies while indicators of early immune system stimulation may include living on a farm, frequent farm visits, early animal exposure or breast feeding. Whereas studies of brain tumours in adults have consistently reported an inverse relationship with atopic conditions [18-20] the findings from studies of CBT, have been more inconsistent [21-23]. Studies to date do not suggest strong associations between living on a farm or early contact with animals [24,25] or breastfeeding [26].

In a previous paper, we reported no associations between breast feeding and CBT [27]. In this study, we aimed to investigate the associations between CBT and the main subtypes with a marker of early infectious exposure (early day-care attendance), history of early common infections, atopic conditions (asthma, eczema, allergic rhinitis) as well as early farm visits, farm residence and animal 
contact in France by pooling data from two nationwide population-based case-control studies, the ESCALE and ESTELLE studies.

\section{Methods}

The ESCALE and ESTELLE studies were designed to investigate the role of environmental and genetic risk factors of childhood cancers including factors related to infections in early life which were conducted with the support of the French society against childhood and adolescent cancers and leukaemias (SFCE). Both studies have been described elsewhere [27-29]. The study protocols complied with the French regulations relating to databases and ethics and the pertinent ethical approvals were obtained. The ESCALE study included children diagnosed in 2003-2004 with a malignant brain tumour as well as children with leukaemia, lymphoma or neuroblastoma. The ESTELLE study included children diagnosed in 2010-2011 with a malignant or non-malignant brain tumour as well as children with a leukaemia, lymphoma, neuroblastoma, Wilms' tumour or hepatoblastoma.

\section{Cases and controls}

In brief, children newly diagnosed with a CBT (defined as group III of ICCC-3) were identified directly in the paediatric oncology departments by the network of the French National Registry of Childhood Cancers (RNCE). Malignant CBT were defined according to the International Classification of Diseases-Oncology (IDCO-3) [30] as tumours with a behaviour code of 3. They were eligible if they were under 15 years of age and resident in mainland France at the time of diagnosis. For both studies children were ineligible if they had been adopted or if the biological mother was not available, did not speak French or had severe psychological or social problems, or if the child was in palliative care or had died (Supplementary Figure S1).

Population controls were selected from French mainland landline telephone subscribers using quota sampling methods. Procedures differed slightly between ESCALE and ESTELLE. For ESCALE, listed and unlisted telephone numbers were randomly generated by incrementing by one the last digit of the listed telephone numbers while for ESTELLE, allocable telephone numbers were randomly generated. Quotas were used to obtain overall at least one control per case for each year of age, each gender and each type of cancer. The quotas also ensured that the control groups had the same distribution as the overall population in regards to the number of children aged less than 15 years living in the household, adjusted by age. Children with a history of cancer were ineligible. Similar to 
cases, children who had been adopted or whose biological mother was not available or did not speak French were ineligible (supplementary Figure S2).

The participation rate in ESCALE was $80.1 \%$ for cases and $71.2 \%$ for controls. In ESTELLE cases participation was $94.1 \%$ and $85.5 \%$ among cases and controls, respectively (Supplementary Figures S1 and S2).

\section{Data collection}

Data were collected using computer assisted structured telephone interviews with case and control mothers carried out by the same trained interviewers. Mothers were also asked to have the child's personal health record with them for the interview so they could confirm relevant details. Mothers of case children were interviewed on average six months after diagnosis. Questions were asked about demographic and socio-economic characteristics, parental occupational exposures, childhood environment and lifestyle.

In both the ESCALE and ESCALE studies, mothers were asked if their child ever attended a day-care centre or another type of external group day-care (shared nanny, private shared child care) and the child's age at the first time of attendance. Mothers were also asked if the child ever had common infections before the age of one year (tonsillitis, otitis, common cold, laryngitis, bronchiolitis, other pulmonary infections, gastroenteritis, urinary tract infections) and the frequency of these illnesses. In addition, they were asked if the child had had any ear-nose-throat (ENT) operations before three years of age. The interviews also contained questions on prior atopic conditions confirmed by a doctor (asthma/wheezing, eczema, hay fever (only in ESTELLE)). If the child ever had asthma/wheezing, they were asked the type of treatment (antihistamine, corticosteroid or bronchodilator). In addition, mothers were also requested to give details of each residence during the child's life. They were also asked to recall if the child had ever visited a farm before the age of one year, the frequency of those potential visits (never, several days per year, several days per month, at least several days per week), and if the child had had regular contact with a wide range of pets (including cats, dogs, birds or rodentsand fish) or farm animals at least once a week during the first year of life including cows, sheep, pigs, horses and poultry).

\section{Data management}

We defined any external childcare as attending either a day-care centre, having a shared nanny, or attending private shared childcare. Children who never had any external childcare were considered to have had only home care. The time periods of interest for both, any external childcare and any day- 
care attendance were 'ever' and before the age of one year. In France, day-care can be attended between the ages of 2 months and three years.

For common infections before the age of one year, we created an index (none, rare $=1-3$ episodes of infections, only one site, intermediate $=1-3$ episodes of infections, 2 or 3 sites, repeated $=4+$ episodes of infections, only one site or 1-3 episodes of infections, 4+ sites) in addition to the separate categories. Common colds and laryngitis were classified as upper respiratory tract infections (URTI) while bronchiolitis and other pulmonary infections were classified as lower respiratory tract infections (LRTI). Any asthma/wheezing treatment was defined as ever receiving antihistamine, corticosteroid or bronchodilator prescribed for asthma. From the list of childhood residences, we determined whether the child had lived on a farm during the first year of life. For the frequency of farm visits, we included children who had ever lived on a farm in the 'several days a week' group (the highest frequency group). In addition to the frequency of farm visits index we classed the children as never or ever visited a farm during first year of life. Because few children were only exposed to other types of animals, we defined pets as cats or dogs, and farm animals as cows, sheep, or pigs. We kept horses in a separate category.

\section{Statistical Analysis}

We restricted the analyses to children aged one year or older to ensure that all cases and controls had had an opportunity to encounter the exposures of interest for the complete first year of life. We calculated odds-ratios (OR) and their 95\% confidence intervals (CI) for all exposures and their association with CBT and the main subtypes comparing cases and controls using unconditional logistic regression models. Heterogeneity between ESCALE and ESTELLE studies was tested with an interaction term between studies and the factor of interest, but as we found none, only the pooled results are presented. Models were only performed if there was a minimum of five cases. We adjusted all models for the quota matching variables sex, and age (in one-year categories) and study (ESCALE, ESTELLE). We also adjusted for birth order and size of urban unit of residence (population < 5000, 5000-99,000, 100,000-1,999,999 and 22,000,000 (Paris urban unit)), which could potentially be related both to study participation and to the variables of interest. In further analyses, we stratified analyses by age group ( $\leq 7$ years / $>7$ years) as associations between exposures in the first year of life and tumour development may be more apparent in younger children. In addition, we ran models including early common infections, day-care attendance and breastfeeding in the same model to assess whether the estimates changed. Similarly, we included farm and animal exposures mutually in the same model. 
As sensitivity analyses, we excluded children who had lived on a farm during the first year of life and children whose mothers had had occupational exposure to pesticides during pregnancy from all analyses concerning farm visits. As further sensitivity analyses, we repeated the analyses excluding children with history of neurofibromatosis. In the ESTELLE study, we also performed analyses excluding cases with a non-malignant CBT and excluding the cases whose families did not have a landline telephone (since this was a condition for control recruitment). All analyses were conducted with Stata (Version 14, College Station, TX, USA).

\section{Results}

The analyses included 469 children diagnosed with a CBT between 1 and 14 years of age (12.2\% ependymomas or choroid plexus tumours, $23.0 \%$ astrocytomas, $40.5 \%$ embryonal tumours, $22.2 \%$ other gliomas, $2.1 \%$ other or unspecified CBT) and 2719 control children (Table 1, supplementary Figure S1). While ESCALE only included cases with malignant CBT, in ESTELLE 20\% of the included tumours were non-malignant.

The age and sex distributions of cases and controls were different as the frequency matching variables, age and sex, were sampled according to the distribution of all cancer diagnoses included in the studies. As additional cancers were investigated in ESTELLE, these control distributions varied between ESCALE and ESTELLE (Table 2). The median ages at date of diagnosis (cases) or interview (controls) were five and six years respectively. Cases were more often boys than controls (59.0\% vs 53.7\%). There was little difference between cases and controls in the mother's level of education while case children tended to live in more populated areas than control children (Table 2). The ESTELLE controls were slightly older and lived in less populated areas and their mothers tended to have been older at the child's birth and more highly educated than the ESCALE controls (Table 2).

\section{Child care attendance and early common infections}

External childcare was reported for $26.0 \%$ of the cases and $29.4 \%$ of the controls (Table 3). Ever attending any external childcare (OR: 1.0, 95\%CI: 0.8-1.3) or ever attending a day-care centre (OR: $0.9,95 \%$ CI: 0.7-1.2) was not associated with the risk of CBT, with similar results for any attendance before the age of one year (Table 3). A history of early common infections before the age of one year, regardless of the frequency index, was not associated with the risk of CBT (OR for repeated infections (the highest frequency category): 0.9, 95\%CI: 0.7-1.2). Among the specific infections only lower respiratory infections were significantly associated with CBT (OR: 0.8, 95\%CI: 0.6-1.0). There was no association with any of the other specific infections nor with having an ENT operation before the age 
of three years (Table 3). The results by CBT subtype were similar, but the estimates were more imprecise due to small numbers. Results were also similar when we included day-care attendance and common infections in the same model or when we adjusted for breastfeeding (results not shown).

\section{Atopic conditions}

Having ever had eczema was slightly more common than having ever had asthma/wheezing. Among control children who had either of these conditions, $19 \%$ had both, $38 \%$ had only asthma/wheezing and $41 \%$ had only eczema. There were no significant association between ever having asthma/wheezing (OR: 0.8, 95\%CI: 0.6-1.1), eczema (OR: 1.0, 95\%CI: 0.7-1.2) or allergic rhinitis (only ESTELLE: OR: 0.9, 95\%CI: 0.5-1.5) with CBT. The results for asthma/wheezing did not change when restricted to those who had reported any treatment for asthma, regardless of type (Table 4). The results by subtype were similar, although more imprecise (Supplementary Table S1).

\section{Farm visits, farm residence and contact with animals}

While only few case or control children $(<2 \%)$ lived on a farm during their first year of life, $21.1 \%$ of the cases and $28.5 \%$ of the controls had visited a farm during this time. No association was seen with ever living on a farm but ever visiting a farm in the first year of life was inversely associated with CBT (OR: 0.6, 95\%CI: 0.5-0.8) (Table 5), with little difference by the frequency of visits. We found that early contact with cats or dogs was inversely associated with the risk of CBT (OR: 0.8, 95\%CI: 0.6-1.0) (Table 5). This association was seen for both cats and dogs individually. On the contrary, we found no significant association between contact with farm animals (OR: 0.7, 95\%CI: 0.4-1.3) or horses (OR: 0.8, 95\%CI: 0.5-1.6) and the risk of CBT. Subtype analyses were imprecise due to small numbers of exposed for many of the animal types but there was no apparent difference by CBT subtypes for either farm visits or animal exposures (Supplementary Table S2). Mutually adjusting for all farm and animal exposure variables in the same model did not change the overall results. When we excluded children who had lived on a farm during the first year of life ( 6 cases, 33 controls) from the farm visit and contact with animals analyses, the results did not change (results not shown). Neither did they change when we excluded the children whose mother were exposed to pesticides in the workplace during pregnancy (11 cases, 60 controls) (results not shown).

\section{Additional analyses and sensitivity analyses}

There was little difference in the results when we stratified the analyses by the child's age group $(\leq 7$ years / > 7 years). Overall, findings remained similar when children with neurofibromatosis (10 cases, 2 controls), or ESTELLE cases with a non-malignant tumour (67 cases) were excluded or when those 
children who were only exposed to other types of pets or farm animals were included (results not shown). There was also little change when the analyses for the ESTELLE study were rerun excluding cases without a telephone landline (56 cases) (results not shown).

\section{Discussion}

In this pooled analyses of two French case-control studies, we found inverse associations between CBT and both visiting a farm and having regular contact with a pet in the first year of life. There was little evidence of an association between any form of external childcare attendance or any atopic condition (diagnosed by a doctor) and CBT. No associations were seen with a general history of common infections in the first year of life. There were no suggestions of differences by subtypes.

Early child day-care centre attendance leads to higher exposure to infections $[10,11]$ which may on increase the probability of infection with specific viruses possibly related to cancer but might also be protective by stimulating the immune system. Only a few previous studies have assessed the association between early child care attendance and the risk of CBT. In line with our findings, two other studies, a Canadian study [14] with 272 CBT cases and the multisite study CEFALO (Denmark, Norway, Sweden, Switzerland) [7] which included children diagnosed between the ages of 7 and 19 years, both found no association with day-care attendance. The United Kingdom Childhood Cancer (UKCCS) study [13] (576 cases) found no association with formal or informal early day-care attendance, but reported that CBT were inversely associated with the broader category of social contacts, which was defined as any form of day-care or regular contact with infants in the first year of life, compared to more isolated children. In contrast, a Danish register-based study case-control study [12] with 170 cases reported a higher risk of CBT among children who attended a day-care centre compared to children who never attended any type of day-care, but not for children attending any kind of external childcare. Unlike the other studies which relied on parental recall, this study linked population-based registers and was therefore less prone to selection bias, but information on childcare was only available for $\sim 50 \%$ children in this study.

In regards to a history of common infections, the CEFALO study [7] found an increased risk of CBT among children who had on average four or more sick days per month during the first six years of life. When restricted to infections in the first year of life the risk was still increased for gliomas and embryonal tumours. As well as differences in the age-range of the children to our study, the way the questions were asked differed as we asked about specific infections, which we used to calculate an index based on the number and the sites of infections, while they asked the mothers to estimate the number of sick days. 
The CEFALO study [21] found no associations between current or past atopic conditions of various types (asthma, wheezing, eczema, allergic rhinitis). By contrast, the UKCCS study [22] found a reduced risk for brain tumours in children that ever had had asthma/wheezing, which was most apparent for embryonal tumours. Similarly, the Canadian study [23] found a protective association with ever being diagnosed with asthma. Even though CIs included unity, our ORs were suggestive of a reduced risk in children ever diagnosed with asthma/wheezing. For adult brain tumours, specifically for gliomas, several studies have also found an inverse relationship between having atopic conditions and tumour development $[19,20,31]$. The immune surveillance hypothesis has been used to explain the inverse associations in adults [32]. It states that an overactive immune system might be better at detecting malignant cells and therefore be protective for potential cancers. However, the immunosuppressive effect of the tumour itself might also have caused the associations and it remains unclear whether the hypothesis also extends to CBT.

Unlike us, three studies [25,33,34] which included cases diagnosed between 1965 and 1994 found some elevated risks of any CBT [25,33] or more specifically, primitive neuroectodermal tumour (PNET) [25,34], among children who had lived on a farm. Two of these studies were conducted in the US, while the third was the large international SEARCH study [25], with a total of 1627 cases, over $40 \%$ of which also came from the US. By contrast, the European CEFALO study, which included cases diagnosed around the same time as our cases [24], had findings more similar to ours. They found a reduced risk for CBT who had been exposed to birds and to goats/sheep and a reduced risk for living on a farm in the first six years of life, but only in the unadjusted model. Exposure to pesticides was suggested as a possible explanation for the positive associations with living on a farm. If this is the case, the difference in findings compared to us may be explained by changes in pesticide use over time or by differing farming practices between the US and France. For example, farms in the US tend to be much larger and aerial spraying more common than in France. In France, the main types of crops grown and the types and pesticides used have changed over the last fifty years [35]. However, in our study, we do not know the types of farms children were living on or visited, so we cannot speculate about the levels or types of possible pesticide exposure. A protective effect of farm visits in early life similar as the hygiene hypothesis proposes for allergies [36] might as well be plausible. Similar assumptions are also discussed for other childhood cancers such as leukaemia [37]. Exposure to a farm environment might lead to a better stimulation of the immune system. In line with this assumption, our results remained stable when we excluded mothers who were occupationally exposed to pesticides during pregnancy. Nevertheless, support for this hypothesis is still weak. Furthermore, we found no strong evidence for a dose-response, which 
weakens the validity of this hypothesis. In addition, it is hard to explain why we found an inverse association with regularly visiting a farm, but not with living on one, although this could be related to lack of statistical power since few children lived on a farm.

Our study had several strengths. The two case-control studies (ESCALE and ESTELLE) were designed to be pooled in order to increase power. All cases were drawn from the population-based national registry of childhood cancers in France which has a high level of nationwide completeness. Control children in both studies were drawn from random telephone subscribers ensuring an equal chance of families with a landline telephone across the country to participate as controls in the study. In addition, the same trained interviewers were used for the interviews with cases and controls. Both studies were, among other factors, specifically designed to study the relationship between infectious exposure and cancers in children and therefore included detailed questions on both individual infections and other proxies for early exposure to infections making it possible investigate individual types of infections.

This study, however, shares problems inherent to all retrospective case-control studies, that is, possible recall or selection biases. Firstly, we cannot rule out that the case mothers might have remembered past illnesses in more detail or taken more time to carefully consider their responses than control mothers. This may particularly apply to recall of specific early infections than to recall of day-care attendance or contact with animals, which may be more objective. However, a differential recall in this direction would rather have led to a positive association with early infection, which was not the case. Even so, non-differential misclassification of prior diseases might have occurred and led to underestimation of associations if both case and control mothers had misreported exposures [38]. However, the UKCCS found that both case and control mothers tended to underreport infectious illnesses to about the same extent [39]. It is also possible that mothers of the older children had difficulty in recalling infections in the child's first year of life. While most mothers had the child's personal health record available, not all common infections may have been well recorded.

Secondly, there may have been selection bias in our studies as not all mothers of children with cancer agreed to participate in the study. Even though participation rate among eligible case mothers was generally high (80\% in ESCALE and 94\% in ESTELLE), we cannot rule out potential differences between participating and non-participating mothers. In addition, we excluded case children with the most severe disease (11\% of total cases), that is those who received palliative care or had died, which may also have increased the risk of selection bias. If we had classed these children as eligible the participation rate would have been $63 \%$ overall. 
Likewise, studies have shown that mothers who participate as controls tend to be older and have a higher socioeconomic status than those who do not, which may lead to spurious estimates [40-42]. This may particularly be a problem in studies like ours which, by design, in addition exclude controls without a fixed telephone line as this may be associated with a range of socioeconomic factors. Nevertheless, this was not a condition for case participation. In the later study, ESTELLE (for which we have these data) about $20 \%$ of the case mothers could only be contacted by mobile phone but exclusion of these did not change our findings. In addition, we made changes to the method of control recruitment between ESCALE and ESTELLE, which resulted in an apparent increase in participation, which seems to contrary to international trends $[43,44]$. In the earlier study (ESCALE) we had used sample lists from actual national telephone company subscribers plus randomly generated unlisted numbers, while in the later study (ESTELLE) we did not use such listed telephone numbers but relied entirely on random samples of numbers (Figure 2 online supplement), which resulted in a higher proportion of both unconnected and unanswered telephones numbers in ESTELLE. If we assume that the proportion of households with eligible children among the households where eligibility could not be assessed was the same as for the contacted subscribers, the true number of eligible children would have been 2011 in ESTELLE and 2436 in ESCALE and the true participation would have been very similar in the two studies (70.9\% and 69.0 in ESTELLE and ESCALE respectively).

Finally, despite having over 400 CBT cases, for some of the exposures such as farm visits and contact with farm animals, relatively few children were exposed, so our estimates were imprecise and we cannot draw any conclusions on whether an association exists. We also could not investigate exposure to other animals (e.g. rodents or birds) because of low numbers. For this reason, as well as multiple testing, we cannot exclude the role of chance. Our findings did not change substantially when subtype analyses were done, but the estimates tended to be underpowered, which limited our ability to detect any heterogeneity between the subtypes. However, it might as well be that the ICCC-3 is not the most relevant classification to investigate aetiology.

\section{Conclusion}

This pooled analysis of two French case-control studies found little evidence of any associations between CBT and any form of childcare including day-care attendance, history of common infections or atopic conditions. We found some evidence of a protective association for early farm visits and contact with pets which might suggest a protective effect through early immune stimulation. Still, in our study, only few children had frequently visited a farm. An alternative explanation for our findings 
could also be bias, chance or unmeasured confounding as the underlying biological mechanism is not clear. As CBT are a very heterogeneous group, subgroup analyses with sufficient power may be important. Pooling case-control studies from different countries may bring further insight into our findings. 


\section{Funding}

The ESCALE and ESTELLE studies were supported by grants from INSERM, the Ligue Nationale Contre le Cancer, the Fondation de France, the Fondation ARC pour la Recherche sur le Cancer, the Agence Française de Sécurité Sanitaire des Produits de Santé (ANSM), the Agence Française de Sécurité Sanitaire de l'Environnement et du Travail (ANSES), the association Cent pour sang la vie, the association Enfants cancer et santé, the Institut National du Cancer (INCa), the Agence Nationale de la Recherche (ANR), the Cancéropôle Ile de France.

JL is supported by a fellowship from Force Fondation Recherche sur le cancer de l'enfant (Lausanne, Switzerland), Bernese Cancer League (Bern, Switzerland) and Swiss National Cancer League.

\section{Acknowledgements}

The authors would also like to thank all of the Société Française de lutte contre les Cancers et les leucémies de l'Enfant et de l'Adolescent (SFCE) principal investigators: Claire Berger (Centre Hospitalier Universitaire, Saint-Etienne), Christophe Bergeron (Centre Léon Bérard, Lyon), JeanLouis Bernard (Hôpital La Timone, Marseille), Yves Bertrand (Hôpital Debrousse, Lyon), Pierre Bordigoni (Centre Hospitalier Universitaire, Nancy), Patrick Boutard (Centre Hospitalier Régional Universitaire, Caen), Pascal Chastagner (Centre Hospitalier Universitaire, Nancy), Philippe Colombat (Centre Gatien de Clocheville, Tours), Gérard Couillault (Hôpital d'Enfants, Dijon), Anne-Sophie Defachelles (Oscar Lambret Comprehensive Cancer Center, Lille), François Demeocq (Hôpital HôtelDieu, Clermont-Ferrand), Alain Fischer (Hôpital des Enfants Malades, Paris), Virginie Gandemer (Centre Hospitalier Universitaire - Hôpital Sud, Rennes), Stéphanie Haouy (Hôpital Arnaud de Villeneuve, Montpellier), Jean-Pierre Lamagnere (Centre Gatien de Clocheville, Tours), Françoise Lapierre (Centre Hospitalier Universitaire Jean Bernard, Poitiers), Patrick Lutz (Hôpital de Hautepierre, Strasbourg), Geneviève Margueritte (Hôpital Arnaud de Villeneuve, Montpellier), Françoise Mechinaud (Hôpital Mère et Enfants, Nantes), Gérard Michel (Hôpital La Timone, Marseille), Jean Michon (Institut Curie, Paris),Frédéric Millot (Centre Hospitalier Universitaire Jean Bernard, Poitiers), Philippe le Moine (Hôpital Morvan, Brest), Martine Münzer (American Memorial Hospital, Reims), Brigitte Nelken (Hôpital Jeanne de Flandre, Lille), Brigitte Pautard (Centre Hospitalier Universitaire, Amiens), Yves Perel (Hôpital Pellegrin Tripode, Bordeaux), Alain PierreKahn (Hôpital Enfants Malades, Paris), Christophe Piguet (Centre Hospitalier Régional Universitaire, Limoges, Dominique Plantaz (Centre Hospitalier Universitaire, Grenoble), Emmanuel Plouvier (Centre Hospitalier Régional, Besançon), Marilyne Poiree (Fondation Lenval, Nice), Xavier Rialland (Centre Hospitalier Universitaire, Angers), Alain Robert (Hôpital des Enfants, Toulouse), Hervé Rubie 
(Hôpital des Enfants, Toulouse), Christian Sainte Rose (Centre Hospitalier Universitaire Necker, Paris), Nicolas Sirvent (Hôpital Arnaud de Villeneuve, Montpellier), Christine Soler (Fondation Lenval, Nice), Dominique Valteau-Couanet (Gustave Roussy, Villejuif), and Jean-Pierre Vannier (Hôpital Charles Nicolle, Rouen). The authors thank all families for their generous participation.

\section{Conflict of interest}

None of the authors has any potential competing financial interests. 


\section{References}

[1] B. Lacour, A. Guyot-Goubin, S. Guissou, S. Bellec, E. Désandes, J. Clavel, Incidence of childhood cancer in France: National Children Cancer Registries, 2000-2004, Eur. J. Cancer Prev. 19 (2010) 173-181. doi:10.1097/CEJ.0b013e32833876c0.

[2] E. Steliarova-Foucher, C. Stiller, B. Lacour, P. Kaatsch, International Classification of Childhood Cancer, third edition, Cancer. 103 (2005) 1457-1467. doi:10.1002/cncr.20910.

[3] B. Lacour, S. Goujon, S. Guissou, A. Guyot-Goubin, S. Desmee, E. Desandes, J. Clavel, Childhood cancer survival in France, 2000-2008, Eur J Cancer Prev. 23 (2014) 449-457. doi:10.1097/CEJ.0000000000000006.

[4] K.J. Johnson, J. Cullen, J.S. Barnholtz-Sloan, Q.T. Ostrom, C.E. Langer, M.C. Turner, R. McKeanCowdin, J.L. Fisher, P.J. Lupo, S. Partap, J.A. Schwartzbaum, M.E. Scheurer, Childhood brain tumor epidemiology: a brain tumor epidemiology consortium review, Cancer Epidemiol Biomarkers Prev. 23 (2014) 2716-2736. doi:10.1158/1055-9965.epi-14-0207.

[5] P.A. McKinney, Central nervous system tumours in children: epidemiology and risk factors, Bioelectromagnetics. Suppl 7 (2005) S60-8. doi:10.1002/bem.20149.

[6] J. Wiemels, Perspectives on the causes of childhood leukemia, Chem Biol Interact. 196 (2012) 59-67. doi:10.1016/j.cbi.2012.01.007.

[7] T. V Andersen, L.S. Schmidt, A.H. Poulsen, M. Feychting, M. Roosli, T. Tynes, D. Aydin, M. Prochazka, B. Lannering, L. Klaeboe, T. Eggen, C.E. Kuehni, K. Schmiegelow, J. Schuz, Patterns of exposure to infectious diseases and social contacts in early life and risk of brain tumours in children and adolescents: an International Case-Control Study (CEFALO), Br J Cancer. 108 (2013) 2346-2353. doi:10.1038/bjc.2013.201.

[8] A.L. Ponsonby, D. Couper, T. Dwyer, A. Carmichael, A. Kemp, Relationship between early life respiratory illness, family size over time, and the development of asthma and hay fever: a seven year follow up study, Thorax. 54 (1999) 664-669.

http://www.ncbi.nlm.nih.gov/pmc/articles/PMC1745551/pdf/v054p00664.pdf.

[9] L.P. Koopman, H.A. Smit, M.L. Heijnen, A. Wijga, R.T. van Strien, M. Kerkhof, J. Gerritsen, B. Brunekreef, J.C. de Jongste, H.J. Neijens, Respiratory infections in infants: interaction of parental allergy, child care, and siblings-- The PIAMA study, Pediatrics. 108 (2001) 943-948.

[10] Y. Sun, J. Sundell, Early daycare attendance increase the risk for respiratory infections and asthma of children, J Asthma. 48 (2011) 790-796.

[11] M. Kamper-Jørgensen, J. Wohlfahrt, J. Simonsen, M. Grønbæk, C.S. Benn, Population-Based Study of the Impact of Childcare Attendance on Hospitalizations for Acute Respiratory Infections, Pediatrics. 118 (2006) 1439-1446. doi:10.1542/peds.2006-0373.

[12] L.S. Schmidt, M. Kamper-Jorgensen, K. Schmiegelow, C. Johansen, P. Lahteenmaki, C. Trager, T. Stokland, K. Grell, G. Gustafson, P. Kogner, A. Sehested, J. Schuz, Infectious exposure in the first years of life and risk of central nervous system tumours in children: analysis of birth order, childcare attendance and seasonality of birth., Br. J. Cancer. 102 (2010) 1670-1675. doi:10.1038/sj.bjc.6605679.

[13] N.J. Harding, J.M. Birch, S.J. Hepworth, P.A. McKinney, Infectious exposure in the first year of life and risk of central nervous system tumors in children: analysis of day care, social contact, 
and overcrowding, Cancer Causes Control. 20 (2009) 129-136. doi:10.1007/s10552-0089224-8.

[14] A.K. Shaw, P. Li, C. Infante-Rivard, Early infection and risk of childhood brain tumors (Canada), Cancer Causes Control. 17 (2006) 1267-1274. doi:10.1007/s10552-006-0066-y.

[15] S. Oksuzyan, C.M. Crespi, M. Cockburn, G. Mezei, L. Kheifets, Birth weight and other perinatal factors and childhood CNS tumors: A case-control study in California, Cancer Epidemiol. 37 (2013) 402-409. doi:10.1016/j.canep.2013.03.007.

[16] J. Von Behren, P. Reynolds, Birth characteristics and brain cancers in young children, Int J Epidemiol. 32 (2003) 248-256.

http://www.ncbi.nlm.nih.gov/entrez/query.fcgi?cmd=Retrieve\&db=PubMed\&dopt=Citation \&list_uids=12714545.

[17] M. Bevier, M. Weires, H. Thomsen, J. Sundquist, K. Hemminki, Influence of family size and birth order on risk of cancer: a population-based study., BMC Cancer. 11 (2011) 163. doi:10.1186/1471-2407-11-163.

[18] H. Zhao, W. Cai, S. Su, D. Zhi, J. Lu, S. Liu, Allergic conditions reduce the risk of glioma: a metaanalysis based on 128,936 subjects, Tumor Biol. 35 (2014) 3875-3880. doi:10.1007/s13277013-1514-4.

[19] C. Chen, T. Xu, J. Chen, J. Zhou, Y. Yan, Y. Lu, S. Wu, Allergy and risk of glioma: a meta-analysis, Eur. J. Neurol. 18 (2011) 387-395. doi:10.1111/j.1468-1331.2010.03187.x.

[20] E. Linos, T. Raine, A. Alonso, D. Michaud, Atopy and risk of brain tumors: a meta-analysis., J. Natl. Cancer Inst. 99 (2007) 1544-50. doi:10.1093/jnci/djm170.

[21] X. Shu, M. Prochazka, B. Lannering, J. Schuz, M. Roosli, T. Tynes, C.E. Kuehni, T. V Andersen, D. Infanger, L.S. Schmidt, A.H. Poulsen, L. Klaeboe, T. Eggen, M. Feychting, Atopic conditions and brain tumor risk in children and adolescents--an international case-control study (CEFALO), Ann Oncol. 25 (2014) 902-908. doi:10.1093/annonc/mdu048.

[22] N.J. Harding, J.M. Birch, S.J. Hepworth, P.A. McKinney, Atopic dysfunction and risk of central nervous system tumours in children, Eur J Cancer. 44 (2008) 92-99. http://ac.elscdn.com/S095980490700799X/1-s2.0-S095980490700799X-main.pdf?_tid=0c7d024a-6cf911e5-9f50-00000aacb361\&acdnat=1444225442_1a648a5ddc8201cf0183324692d34ddc.

[23] F. Roncarolo, C. Infante-Rivard, Asthma and risk of brain cancer in children, Cancer Causes Control. 23 (2012) 617-623.

[24] J.S. Christensen, L.H. Mortensen, M. Roosli, M. Feychting, T. Tynes, T. V Andersen, L.S. Schmidt, A.H. Poulsen, D. Aydin, C.E. Kuehni, M. Prochazka, B. Lannering, L. Klaeboe, T. Eggen, J. Schuz, Brain tumors in children and adolescents and exposure to animals and farm life: a multicenter case-control study (CEFALO), Cancer Causes Control. (2012). doi:10.1007/s10552-012-0020-0.

[25] J.T. Efird, E.A. Holly, S. Preston-Martin, B.A. Mueller, F. Lubin, G. Filippini, R. Peris-Bonet, M. McCredie, S. Cordier, A. Arslan, P.M. Bracci, Farm-related exposures and childhood brain tumours in seven countries: results from the SEARCH International Brain Tumour Study, Paediatr. Perinat. Epidemiol. 17 (2003) 201-211. doi:10.1046/j.1365-3016.2003.00484.x.

[26] R.M. Martin, D. Gunnell, C.G. Owen, G.D. Smith, Breast-feeding and childhood cancer: A systematic review with metaanalysis, Int. J. Cancer. 117 (2005) 1020-1031. 
doi:10.1002/ijc.21274.

[27] H.D. Bailey, P. Rios, B. Lacour, L. Guerrini-Rousseau, A.-I. Bertozzi, P. Leblond, C. FaureConter, I. Pellier, C. Freycon, J. Michon, S. Puget, S. Ducassou, L. Orsi, J. Clavel, Factors related to pregnancy and birth and the risk of childhood brain tumours: The ESTELLE and ESCALE studies (SFCE, France), Int. J. Cancer. 140 (2017) 1757-1769. doi:10.1002/ijc.30597.

[28] R. Ajrouche, J. Rudant, L. Orsi, A. Petit, A. Baruchel, B. Nelken, M. Pasquet, G. Michel, C. Bergeron, S. Ducassou, V. Gandemer, P. Lutz, L. Saumet, X. Rialland, D. Hemon, J. Clavel, Maternal reproductive history, fertility treatments and folic acid supplementation in the risk of childhood acute leukemia: the ESTELLE study, Cancer Causes Control. 25 (2014) 12831293. doi:10.1007/s10552-014-0429-8.

[29] N. Mallol-Mesnard, F. Menegaux, B. Lacour, O. Hartmann, D. Frappaz, F. Doz, A.I. Bertozzi, P. Chastagner, D. Hemon, J. Clavel, Birth characteristics and childhood malignant central nervous sytem tumors: the ESCALE study (French Society for Childhood Cancer), Cancer Detect Prev. 32 (2008) 79-86.

[30] WHO, International Classification of Diseases for Oncology, 3rd ed., World Health Organization (WHO), Geneva, Switzerland, 2013.

[31] H. Zhao, W. Cai, S. Su, D. Zhi, J. Lu, S. Liu, Allergic conditions reduce the risk of glioma: a metaanalysis based on 128,936 subjects, Tumor Biol. 35 (2014) 3875-3880. doi:10.1007/s13277013-1514-4.

[32] G.P. Dunn, L.J. Old, R.D. Schreiber, The Immunobiology of Cancer Immunosurveillance and Immunoediting, Immunity. 21 (2004) 137-148. doi:http://dx.doi.org/10.1016/j.immuni.2004.07.017.

[33] E. Gold, L. Gordis, J. Tonascia, M. Szklo, Risk factors for brain tumors in children., Am. J. Epidemiol. 109 (1979) 309-19. doi:10.1093/OXFORDJOURNALS.AJE.A112684.

[34] G.R. Bunin, J.D. Buckley, C.P. Boesel, L.B. Rorke, A.T. Meadows, Risk factors for astrocytic glioma and primitive neuroectodermal tumor of the brain in young children: a report from the Children's Cancer Group., Cancer Epidemiol. Prev. Biomarkers. 3 (1994). http://cebp.aacrjournals.org/content/3/3/197.long (accessed April 28, 2017).

[35] I. Baldi, C. Carles, A. Blanc-Lapierre, P. Fabbro-Peray, M. Druet-Cabanac, E. Boutet-Robinet, J.M. Soulat, G. Bouvier, P. Lebailly, M. Barrau, L. Creppy, C. LarvinCardo, Y. Lecluse, E. Niez, E. Parent, N. Rabier, X. Schwall, A French crop-exposure matrix for use in epidemiological studies on pesticides: PESTIMAT, J. Expo. Sci. Environ. Epidemiol. 27 (2017) 56-63. doi:10.1038/jes.2015.72.

[36] B. Schaub, R. Lauener, E. von Mutius, The many faces of the hygiene hypothesis, J Allergy Clin Immunol. 117 (2006) 969-977. http://ac.els-cdn.com/S0091674906006452/1-s2.0S0091674906006452-main.pdf?_tid=a5b039d4-376e-11e5-85b300000aacb362\&acdnat=1438338587_e56e19c98a04321d1c766bd0791b6354.

[37] T. Eden, Aetiology of childhood leukaemia, Cancer Treat Rev. 36 (2010) 286-297. doi:10.1016/j.ctrv.2010.02.004.

[38] K.J. Rothman, S. Greenland, T.L. Lash, Modern epidemiology, Lippincott Williams \& Wilkins, 2008.

[39] J. Simpson, A. Smith, P. Ansell, E. Roman, Childhood leukaemia and infectious exposure: a 
report from the United Kingdom Childhood Cancer Study (UKCCS), Eur J Cancer. 43 (2007) 2396-2403. doi:10.1016/j.ejca.2007.07.027.

[40] G.R. Law, A.G. Smith, E. Roman, The importance of full participation: lessons from a national case-control study, Br J Cancer. 86 (2002) 350-355. doi:10.1038/sj.bjc.6600092.

[41] G. Mezei, L. Kheifets, Selection bias and its implications for case-control studies: a case study of magnetic field exposure and childhood leukaemia, Int J Epidemiol. 35 (2006) 397-406. http://www.ncbi.nlm.nih.gov/entrez/query.fcgi?cmd=Retrieve\&db=PubMed\&dopt=Citation \&list_uids=16303812.

[42] J. Schüz, Non-response bias as a likely cause of the association between young maternal age at the time of delivery and the risk of cancer in the offspring., Paediatr. Perinat. Epidemiol. 17 (2003) 106-12. http://www.ncbi.nlm.nih.gov/pubmed/12562478 (accessed March 16, 2017).

[43] M. Mazloum, H.D. Bailey, T. Heiden, B.K. Armstrong, N. de Klerk, E. Milne, Participation in population-based case-control studies: does the observed decline vary by socio-economic status?, Paediatr. Perinat. Epidemiol. 26 (2012) 276-279. doi:10.1111/j.13653016.2011.01253.x.

[44] G.R. Bunin, L.G. Spector, A.F. Olshan, L.L. Robison, M. Roesler, S. Grufferman, X. -o. Shu, J.A. Ross, Secular Trends in Response Rates for Controls Selected by Random Digit Dialing in Childhood Cancer Studies: A Report from the Children's Oncology Group, Am. J. Epidemiol. 166 (2007) 109-116. doi:10.1093/aje/kwm050. 
Published in final edited form as: Cancer Epidemiol. 2018 Feb;52:1-9. doi: 10.1016/j.canep.2017.10.015

Table 1: Distribution of cases aged 1 to 14 years according to the International Classification of Childhood Cancer $3^{\text {rd }}$ Revision (ICCC-3) and to the international classification of diseases-oncology (ICDO3) class of behaviour

\begin{tabular}{|c|c|c|c|c|c|c|}
\hline & \multirow{2}{*}{\multicolumn{2}{|c|}{ COMBINED }} & \multirow{2}{*}{\multicolumn{2}{|c|}{ ESCALE }} & \multirow{2}{*}{\multicolumn{2}{|c|}{ ESTELLE }} \\
\hline & & & & & & \\
\hline & \multicolumn{2}{|c|}{$\mathrm{n}=469$} & \multicolumn{2}{|c|}{$\mathrm{n}=191$} & \multicolumn{2}{|c|}{$\mathrm{n}=278$} \\
\hline ICCC-3 subgroups of group 3 & $\mathrm{n}$ & $\%$ & $\mathrm{n}$ & $\%$ & $\mathrm{n}$ & $\%$ \\
\hline $\begin{array}{l}\text { 3a - Ependymomas and choroid plexus } \\
\text { tumours }\end{array}$ & & & & & & \\
\hline Malignant (ICDO-3 behaviour=3) & 56 & 11.9 & 29 & 15.2 & 27 & 9.7 \\
\hline Non malignant (ICDO-3 behaviour $<3$ ) & 1 & 0.2 & 0 & 0.0 & 1 & 0.4 \\
\hline total & 57 & 12.2 & 29 & 15.2 & 28 & 10.1 \\
\hline \multicolumn{7}{|l|}{ 3b - Astrocytomas } \\
\hline Malignant (ICDO-3 behaviour /3) & 62 & 13.2 & 24 & 12.6 & 38 & 13.7 \\
\hline Non malignant & 46 & 9.8 & 0 & 0.0 & 46 & 16.5 \\
\hline total & 108 & 23.0 & 24 & 12.6 & 84 & 30.2 \\
\hline $\begin{array}{l}\text { 3c - Intracranial and intraspinal embryonal } \\
\text { tumours (all malignant) }\end{array}$ & 190 & 40.5 & 92 & 48.2 & 98 & 35.3 \\
\hline \multicolumn{7}{|l|}{ 3d - Other gliomas } \\
\hline Malignant (ICDO-3 behaviour /3) & 84 & 17.9 & 42 & 22.0 & 42 & 15.1 \\
\hline Non malignant & 20 & 4.3 & 0 & 0.0 & 20 & 7.2 \\
\hline total & 104 & 22.2 & 42 & 22.0 & 62 & 22.3 \\
\hline $\begin{array}{l}\text { 3e - Other specified intracranial and intraspi } \\
\text { (ICDO-3 behaviour /3) (all malignant) }\end{array}$ & 8 & 1.7 & 2 & 1.0 & 6 & 2.2 \\
\hline $\begin{array}{l}\text { 3f - Unspecified intracranial and intraspinal } \\
\text { neoplasm (all malignant) }\end{array}$ & 2 & 0.4 & 2 & 1.0 & 0 & 0.0 \\
\hline
\end{tabular}

ICCC-3 : International Classification of Childhood Cancer $3^{\text {rd }}$ Revision

ICDO-3 International Classification of Diseases-Oncology 
Published in final edited form as: Cancer Epidemiol. 2018 Feb;52:1-9. doi: 10.1016/j.canep.2017.10.015 Table 2: Characteristics of study cases and controls aged 1 to 14 years

\begin{tabular}{|c|c|c|c|c|c|c|c|c|c|c|c|c|c|c|c|}
\hline & \multicolumn{5}{|c|}{ COMBINED } & & & \multicolumn{4}{|c|}{ ESCALE } & \multicolumn{4}{|c|}{ ESTELLE } \\
\hline & \multicolumn{2}{|c|}{$\begin{array}{c}\text { cases } \\
(\mathrm{n}=469)\end{array}$} & \multicolumn{2}{|c|}{$\begin{array}{l}\text { controls } \\
(\mathrm{n}=2719)\end{array}$} & \multirow{2}{*}{$\begin{array}{c}\begin{array}{c}\text { Case-control } p \\
\text { value }^{\mathrm{a}}\end{array} \\
\mathrm{p} \\
\end{array}$} & \multirow{2}{*}{$\begin{array}{c}\text { Between } \\
\text { studies } p \\
\text { value }^{\mathrm{b}}\end{array}$} & \multirow[t]{2}{*}{$\begin{array}{c}\text { Case/control } \\
\text { ratio } \\
\end{array}$} & \multicolumn{2}{|c|}{$\begin{array}{c}\text { cases } \\
(\mathrm{n}=191)\end{array}$} & \multicolumn{2}{|c|}{$\begin{array}{l}\text { controls } \\
(n=1494)\end{array}$} & \multicolumn{2}{|c|}{$\begin{array}{c}\text { cases } \\
(n=278)\end{array}$} & \multicolumn{2}{|c|}{$\begin{array}{l}\text { controls } \\
(\mathrm{n}=1225)\end{array}$} \\
\hline & $\mathrm{n}$ & $\%$ & $\mathrm{n}$ & $\%$ & & & & $\mathrm{n}$ & $\%$ & $\mathrm{n}$ & $\%$ & $\mathrm{n}$ & $\%$ & $\mathrm{n}$ & $\%$ \\
\hline \multicolumn{16}{|c|}{ Age (years) } \\
\hline 1 & 48 & 10.2 & 303 & 11.1 & $<0.001$ & $<0.001$ & 6.3 & 16 & 8.4 & 182 & 12.2 & 32 & 11.5 & 121 & 9.9 \\
\hline 2 & 46 & 9.8 & 297 & 10.9 & & & 6.5 & 15 & 7.9 & 153 & 10.2 & 31 & 11.2 & 144 & 11.8 \\
\hline 3 & 49 & 10.4 & 310 & 11.4 & & & 6.3 & 17 & 8.9 & 166 & 11.1 & 32 & 11.5 & 144 & 11.8 \\
\hline 4 & 46 & 9.8 & 274 & 10.1 & & & 6.0 & 25 & 13.1 & 145 & 9.7 & 21 & 7.6 & 129 & 10.5 \\
\hline $5-6$ & 83 & 17.7 & 417 & 15.3 & & & 5.0 & 34 & 17.8 & 228 & 15.3 & 49 & 17.6 & 189 & 15.4 \\
\hline $7-8$ & 75 & 16.0 & 256 & 9.4 & & & 3.4 & 33 & 17.3 & 163 & 10.9 & 42 & 15.1 & 93 & 7.6 \\
\hline $9-11$ & 60 & 12.8 & 356 & 13.1 & & & 5.9 & 27 & 14.1 & 225 & 15.1 & 33 & 11.9 & 131 & 10.7 \\
\hline $12-14$ & 62 & 13.2 & 506 & 18.6 & & & 8.2 & 24 & 12.6 & 232 & 15.5 & 38 & 13.7 & 274 & 22.4 \\
\hline \multicolumn{16}{|c|}{ Gender } \\
\hline Girl & 194 & 41.4 & 1260 & 46.3 & 0.045 & 0.071 & 6.5 & 75 & 39.3 & 669 & 44.8 & 119 & 42.8 & 591 & 48.2 \\
\hline Boy & 275 & 58.6 & 1459 & 53.7 & & & 5.3 & 116 & 60.7 & 825 & 55.2 & 159 & 57.2 & 634 & 51.8 \\
\hline \multicolumn{16}{|c|}{ Breast feeding } \\
\hline Never & 202 & 43.1 & 1237 & 45.5 & 0.364 & $<0.001$ & & 86 & 45.0 & 740 & 49.5 & 116 & 41.7 & 497 & 40.6 \\
\hline Ever & 267 & 56.9 & 1482 & 54.5 & & & & 105 & 55.0 & 754 & 50.5 & 162 & 58.3 & 728 & 59.4 \\
\hline \multicolumn{16}{|c|}{ Birth order } \\
\hline 1 & 195 & 41.6 & 1136 & 41.8 & 0.087 & 0.580 & & 75 & 39.3 & 628 & 42.0 & 120 & 43.2 & 508 & 41.5 \\
\hline 2 & 188 & 40.1 & 966 & 35.5 & & & & 85 & 44.5 & 536 & 35.9 & 103 & 37.1 & 430 & 35.1 \\
\hline 3 & 86 & 18.3 & 617 & 22.7 & & & & 31 & 16.2 & 330 & 22.1 & 55 & 19.7 & 287 & 23.4 \\
\hline
\end{tabular}


Published in final edited form as: Cancer Epidemiol. 2018 Feb;52:1-9. doi: 10.1016/j.canep.2017.10.015

\begin{tabular}{|c|c|c|c|c|c|c|c|c|c|c|c|c|c|c|}
\hline$<25$ & 50 & 10.7 & 274 & 10.1 & 0.157 & $<0.001$ & 16 & 8.4 & 151 & 10.1 & 34 & 12.2 & 123 & 10.0 \\
\hline $25-29$ & 188 & 40.1 & 968 & 35.6 & & & 76 & 39.8 & 576 & 38.6 & 112 & 40.3 & 392 & 32.0 \\
\hline $30-34$ & 151 & 32.2 & 962 & 35.4 & & & 68 & 35.6 & 518 & 34.7 & 83 & 29.9 & 444 & 36.2 \\
\hline$\geq 35$ & 80 & 17.1 & 515 & 18.9 & & & 31 & 16.2 & 249 & 16.7 & 49 & 17.6 & 266 & 21.7 \\
\hline \multicolumn{15}{|l|}{ Mother's education } \\
\hline$\leq$ Secondary education & 261 & 55.7 & 1525 & 56.1 & 0.917 & $<0.001$ & 115 & 60.2 & 901 & 60.3 & 146 & 52.5 & 624 & 51.0 \\
\hline Tertiary education & 208 & 44.3 & 1192 & 43.9 & & & 76 & 39.8 & 592 & 39.7 & 132 & 47.5 & 600 & 49.0 \\
\hline Missing & & & 2 & & & & & & 1 & & & & 1 & \\
\hline \multicolumn{15}{|c|}{ Size of urban unit of residence (population) } \\
\hline$<5,000$ & 168 & 36.3 & 1038 & 38.3 & 0.045 & $<0.001$ & 59 & 31.7 & 527 & 35.3 & 109 & 39.4 & 511 & 41.9 \\
\hline $5,000-99,999$ & 84 & 18.1 & 622 & 22.9 & & & 33 & 17.7 & 349 & 23.4 & 51 & 18.4 & 273 & 22.4 \\
\hline $100,000-1,999,999$ & 127 & 27.4 & 624 & 23.0 & & & 50 & 26.9 & 398 & 26.6 & 77 & 27.8 & 226 & 18.5 \\
\hline$\geq 2,000,000$ (Paris unit) & 84 & 18.1 & 429 & 15.8 & & & 44 & 23.7 & 220 & 14.7 & 40 & 14.4 & 209 & 17.1 \\
\hline Missing & 6 & & 6 & & & & 5 & & & & 1 & & 6 & \\
\hline
\end{tabular}

a p-value from likelihood ratio test comparing cases and controls adjusted for age and gender; ESCALE and ESTELLE combined p-value from likelihood ratio test comparing ESCALE and ESTELLE controls, adjusted for age and gender 
Published in final edited form as: Cancer Epidemiol. 2018 Feb;52:1-9. doi: 10.1016/j.canep.2017.10.015 Table3: Associations between childcare attendance, infections and the risk of CBT (children aged 1-14 years)

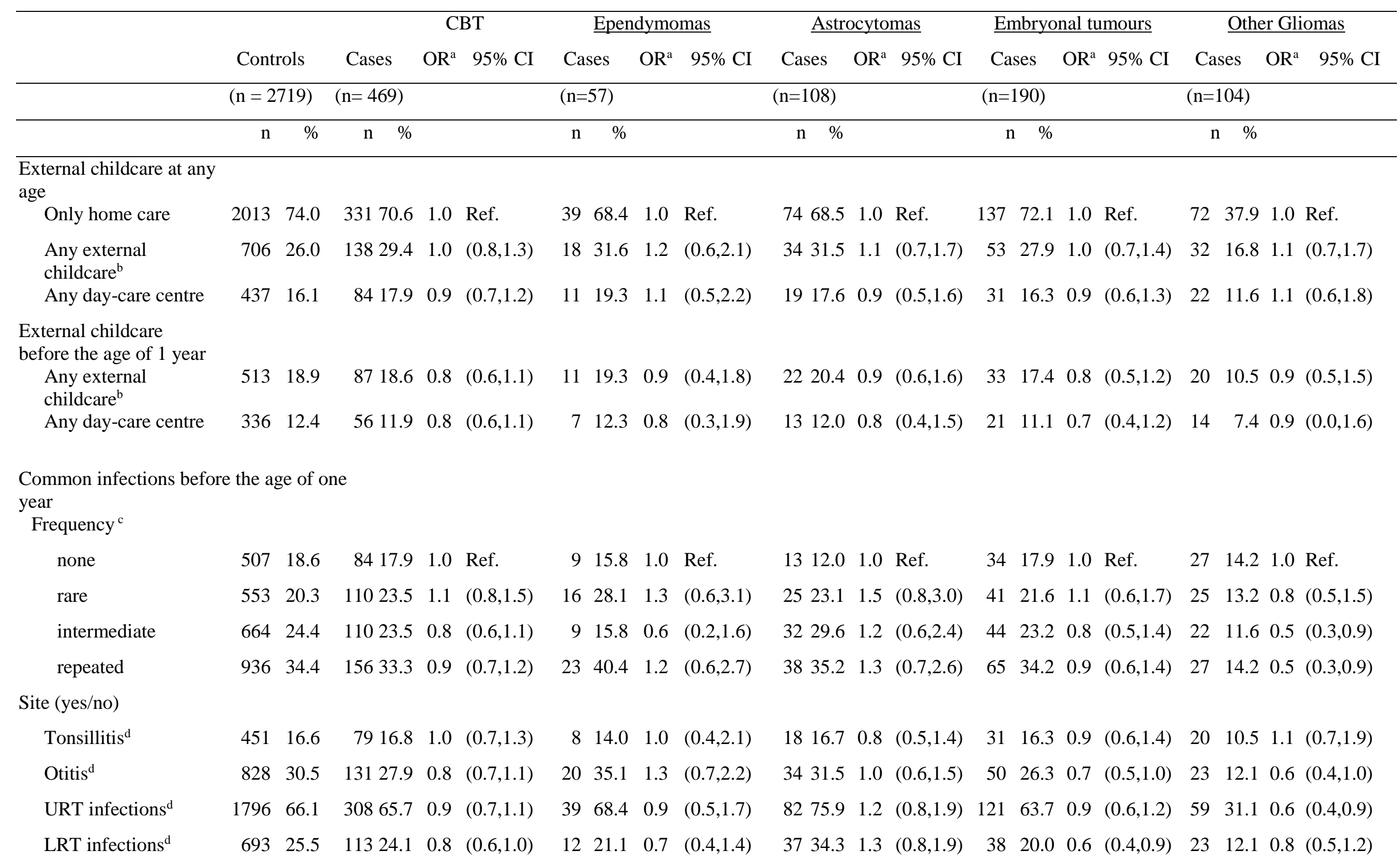




\section{Gastroenteritis $^{\mathrm{d}}$}

Urinary tract infections $^{\mathrm{d}}$

Any ENT operations before the age of 3 years
Published in final edited form as: Cancer Epidemiol. 2018 Feb;52:1-9. doi: 10.1016/j.canep.2017.10.015

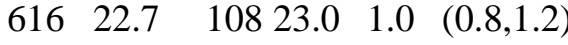
$\begin{array}{llll}8 & 14.0 & 0.5 & (0.2,1.1)\end{array}$
$2422.20 .9(0.5,1.4)$
5126.81 .3
$(0.9,1.8)$

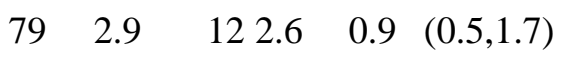
23.5
$\begin{array}{ll}4 & 3.7\end{array}$
$5 \quad 2.6 \quad 1.0(0.4,2.4)$

$23 \quad 12.11 .0(0.6,1.6)$

$\begin{array}{llllllll}5 & 8.8 & 1.5 & (0.5,4.3) & 10.0 & 9.3 & 1.4 & (0.7,2.9)\end{array}$

$10 \quad 5.3 \quad 0.8 \quad(0.4,1.5)$

$5 \quad 2.6 \quad 0.7 \quad(0.3,1.7)$

$\mathrm{CBT}=$ childhood brain tumours; $\mathrm{OR}=$ odds ratio; $\mathrm{CI}=$ confidence interval ENT $=$ Ear nose throat; URT = upper respiratory tract infections; LRT = lower respiratory tract infections; Ref. = reference category

a All analyses adjusted for frequency matching variables age and sex; study (ESCALE, ESTELLE), size of urban unit of residence, and birth order. Logistic regression models only run when there were five or more cases.

b Definition: attending either a day-care centre, having a shared nanny, or attending private shared childcare.

c None $=$ did not have any of these infections, rare $=1-3$ episodes of infections, only one site, intermediate $=1-3$ episodes of infections, 2 or 3 sites, repeated $=4+$ episodes of infections, only one site or 1-3 episodes of infections, 4+ sites.

d Reference category: children who had never had that particular infection. 
Published in final edited form as: Cancer Epidemiol. 2018 Feb;52:1-9. doi: 10.1016/j.canep.2017.10.015 Table 4: History of atopic conditions and the risk of CBT (children aged 1-14 years)

\begin{tabular}{|c|c|c|c|c|c|c|}
\hline & Controls & & Cases & & $\mathrm{OR}^{\mathrm{a}}$ & $95 \% \mathrm{CI}$ \\
\hline & $(n=2719)$ & & $(n=469)$ & & & \\
\hline & $\mathrm{n}$ & $\%$ & $\mathrm{n}$ & $\%$ & & \\
\hline \multicolumn{7}{|l|}{ Asthma/Wheezing } \\
\hline never & 2175 & 80.0 & 390 & 83.2 & 1.0 & Ref. \\
\hline ever & 536 & 19.7 & 77 & 16.4 & 0.8 & $(0.6,1.1)$ \\
\hline with any treatment & 278 & 10.2 & 48 & 10.2 & 0.8 & $(0.6,1.1)$ \\
\hline antihistamine & 179 & 6.6 & 25 & 5.3 & 0.7 & $(0.5,1.1)$ \\
\hline corticosteroid & 217 & 8.0 & 36 & 7.7 & 0.8 & $(0.6,1.2)$ \\
\hline bronchodilator & 265 & 9.7 & 45 & 9.6 & 0.8 & $(0.6,1.1)$ \\
\hline \multicolumn{7}{|l|}{ Eczema } \\
\hline never & 2173 & 79.9 & 378 & 80.6 & 1.0 & Ref. \\
\hline ever & 539 & 19.8 & 89 & 19.0 & 1.0 & $(0.7,1.2)$ \\
\hline ESTELLE only & $(\mathrm{n}=1225)$ & & $(n=278)$ & & & \\
\hline \multicolumn{7}{|l|}{ Allergic rhinitis } \\
\hline never & 1114 & 90.9 & 257 & 92.4 & 1.0 & Ref. \\
\hline ever & 105 & 8.6 & 21 & 7.6 & 0.9 & $(0.5,1.5)$ \\
\hline
\end{tabular}

$\mathrm{CBT}=$ childhood brain tumours; $\mathrm{OR}=$ odds ratio; $\mathrm{CI}$ = confidence interval; Ref. = reference category

a All analyses adjusted for frequency matching variables age and sex; study (ESCALE, ESTELLE), size of urban unit of residence, and birth order. 
Published in final edited form as: Cancer Epidemiol. 2018 Feb;52:1-9. doi: 10.1016/j.canep.2017.10.015 
Published in final edited form as: Cancer Epidemiol. 2018 Feb;52:1-9. doi: 10.1016/j.canep.2017.10.015 Table 5: Associations between visiting a farm, contact with animals and CBT (children aged 1-14 years)

\begin{tabular}{|c|c|c|c|c|c|c|}
\hline & Controls & & Cases & & $\mathrm{OR}^{\mathrm{a}}$ & $95 \%$ CI \\
\hline & $(n=2719)$ & & $n=469)$ & & & \\
\hline Exposure before the age of one year & $\mathrm{n}$ & $\%$ & $\mathrm{n}$ & $\%$ & & \\
\hline \multicolumn{7}{|l|}{ Living farm } \\
\hline no & 2686 & 98.8 & 463 & 98.7 & 1.0 & Ref. \\
\hline yes & 33 & 1.2 & 6 & 1.3 & 1.3 & $(0.5,3.2)$ \\
\hline \multicolumn{7}{|l|}{ Farm visits } \\
\hline never & 1933 & 71.1 & 368 & 78.5 & 1.0 & Ref. \\
\hline ever $^{\mathrm{b}}$ & 776 & 28.5 & 99 & 21.1 & 0.6 & $(0.5,0.8)$ \\
\hline several days/year & 441 & 16.2 & 58 & 12.4 & 0.6 & $(0.4,0.8)$ \\
\hline several days/month & 153 & 5.6 & 23 & 4.9 & 0.8 & $(0.5,1.2)$ \\
\hline several days/week ${ }^{\mathrm{b}}$ & 182 & 6.7 & 18 & 3.8 & 0.6 & $(0.4,1.0)$ \\
\hline \multicolumn{7}{|l|}{ Contact with pets } \\
\hline no & 1150 & 42.3 & 227 & 48.4 & 1.0 & Ref. \\
\hline yes & 1569 & 57.7 & 242 & 51.6 & 0.8 & $(0.6,1.0)$ \\
\hline cats & 933 & 34.3 & 141 & 30.1 & 0.8 & $(0.6,1.0)$ \\
\hline dogs & 1219 & 44.8 & 178 & 38.0 & 0.8 & $(0.6,1.0)$ \\
\hline \multicolumn{7}{|l|}{ Contact with farm animals } \\
\hline no & 2584 & 95.0 & 455 & 97.0 & 1.0 & Ref. \\
\hline yes & 135 & 5.0 & 14 & 3.0 & 0.7 & $(0.4,1.3)$ \\
\hline cows & 105 & 3.9 & 7 & 1.5 & 0.5 & $(0.2,1.1)$ \\
\hline sheep & 67 & 2.5 & 7 & 1.5 & 0.8 & $(0.3,1.7)$ \\
\hline pigs & 31 & 1.1 & 5 & 1.1 & 1.2 & $(0.4,3.1)$ \\
\hline
\end{tabular}

Contact with horses 
Published in final edited form as: Cancer Epidemiol. 2018 Feb;52:1-9. doi: 10.1016/j.canep.2017.10.015

no

2625

96.5

457

$97.4 \quad 1.0$

Ref.

yes

$\begin{array}{llllll}93 & 3.4 & 12 & 2.6 & 0.8 & (0.5,1.6)\end{array}$

$\mathrm{CBT}=$ childhood brain tumours, $\mathrm{OR}=$ odds ratio; $\mathrm{CI}=$ confidence interval; Ref. = reference category

${ }^{a}$ All analyses adjusted for frequency matching variables age and sex; study (ESCALE, ESTELLE), size of urban unit of residence, birth order.

${ }^{\mathrm{b}}$ Category includes children living on a farm during first year of life 